\title{
Mitigation of the Most Hazardous Tank at the Hanford Site
}

\author{
D. A. Reynolds
}

Date Published

September 1994

To Be Presented at

The American Chemical

Society Conference

Atlanta, Georgia

September $19-21,1994$

Prepared for the U.S. Department of Energy

Office of Environmental Restoration and

Waste Management

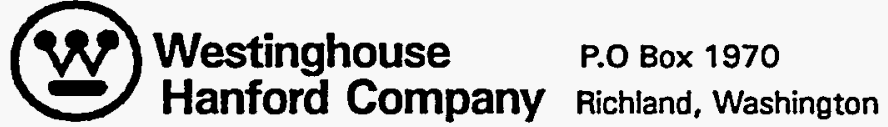

Hanford Operations and Engineering Contractor for the U.S. Department of Energy under Contract DE-AC06-87RL10930

Copyright License By ecceptance of this article, the publisher and/or rocipient acknowlodges the U.S. Govemment's right to retain a nonexclusive, royalty-freo licenso in and to any copyright covering this paper. 


\section{DISCLAIMER}

This report was prepared as an account of work sponsored by an agency of the United States Government. Neither the United States Government nor any agency thereof, nor any of their employees, make any warranty, express or implied, or assumes any legal liability or responsibility for the accuracy, completeness, or usefulness of any information, apparatus, product, or process disclosed, or represents that its use would not infringe privately owned rights. Reference herein to any specific commercial product, process, or service by trade name, trademark, manufacturer, or otherwise does not necessarily constitute or imply its endorsement, recommendation, or favoring by the United States Government or any agency thereof. The views and opinions of authors expressed herein do not necessarily state or reflect those of the United States Government or any agency thereof. 


\section{DISCLAIMER}

\section{Portions of this document may be illegible in electronic image products. Images are produced from the best available original document.}




\title{
MITIGATION OF THE MOST HAZARDOUS \\ TANK AT THE HANFORD SITE
}

\author{
D. A. Reynolds \\ J. H. Lentsch \\ H. Babad \\ C. E. Hanson \\ N. W. Kirch \\ J. A. Lechelt
}

\section{ABSTRACT}

Various tanks at the Hanford Site have been declared to be unresolved safety problems. This means that the tank has the potential to be beyond the limits covered by the current safety documentation. Tank 241-SY-101 poses the greatest hazard. The waste stored in this tank has periodically released hydrogen gas which exceeds the lower flammable limits.

A mixer pump was installed in this tank to stir the waste. Stirring the waste would allow the hydrogen to be released slowly in a controlled manner and mitigate the hazard associated with this tank. The testing of this mixer pump is reported in this document. The mixer pump has been successful in controlling the hydrogen concentration in the tank dome to below the flammable 7imit which has mitigated the hazardous gas releases. 


\section{Introduction}

Double-she11 tank 241-SY-101 (101-SY), containing stored high-level waste at the Hanford Site, is one of a group of Hatch List tanks that poses a unique problem to safe interim storage of wastes at the Hanford Site. This tank contains approximately $3.8 \mathrm{M} \mathrm{L} \mathrm{(1} \mathrm{M} \mathrm{gal)} \mathrm{of} \mathrm{caustic} \mathrm{fuel} \mathrm{reprocessing} \mathrm{waste,}$ with approximately $3 \mathrm{M}$ curies of radioactivity (mostly ${ }^{137} \mathrm{CS}$ ). Every 100 to 150 days the tank accumulated and released sufficient quantities of hydrogen and nitrous oxide gas to exceed the lower flammability limit in the tank dome space and, for approximately 5 minutes each year, exceeds the lower flammability limit in the ventilation header. The releases occur as a result of a somewhat dramatic rollover, or up-welling, of the waste due to buoyant forces resulting from the accumulation of gases in the lower region of the tank. Such releases of flammable gas pose a threat to the containment of the wastes if the gas should ignite. Tank 101-SY is an extreme example of periodic gas releases in waste tanks at the Hanford Site.

To ensure tank safety with 101-SY, a project was started to mitigate the rollover phenomenon. Mitigation success criteria was set at keeping the dome space below $25 \%$ of the 7 ower flammable limit. This paper will report on the success of that mitigation effort.

\section{Problem in 101-SY}

\section{A Brief Description of the Tank Conditions}

The waste in 101-SY is a combination of complexed concentrate waste and double-shell slurry waste. Complexed concentrate is concentrated waste with high levels of water soluble complexants such as citratic acid, $\mathrm{N}$-(2-hydroxyethyl)ethylenediaminetriacetic acid (HEDTA), and ethylenediamine tetraacetic acid (EDTA). Double-shell slurry is the most concentrated slurry that the Hanford evaporators can produce. Double-shell slurry is comprised of sodium salts of nitrate, hydroxide, nitrite, carbonate, soluble organic ions, and aluminate (Reynolds and Babad 1994).

The waste from 101-SY has segregated into three distinct layers. The bottom 5 meters (200 inches) is mostly a settled solid bed. This is termed the nonconvective layer because there is no indication of convective motion in this layer. The next 4 meters is a fluid zone called the convective layer. This layer seems to be mostly liquid with perhaps $20 \%$ suspended solids. On top is a floating crust about 1 meter thick. This crust is solids similar in composition to the nonconvective layer that contains enough gas bubbles to cause the crust to float.

\section{Gas Generation and Retention}

The flammable gas that is being generated in the waste in 101-SY includes hydrogen, nitrogen, nitrous oxide, and ammonia. The gas is generated by the degradation of organic complexants influenced by radiation, heat, and the nitrate and nitrite ions in the waste. 
The gas being generated is retained in the lower nonconvective layer under hydrostatic pressure of approximately 2 atmospheres. The solids in the nonconvective layer have a relatively high shear strength, which provides the strength necessary to keep the gas at the bottom of the tank.

The gas is generated throughout the tank but the gas generated in the fluid convective layer can escape from the tank. Gas is generated at approximately $4 \mathrm{~m}^{3}\left(140 \mathrm{ft}^{3}\right)$ per day. Approximately half of the gas is released and half of the gas is retained.

\section{Rollover}

Gas accumulates in the nonconvective zone until the buoyancy force of the gas is greater than the shear strength of the solids. At that point the solids break loose and raise to the surface. This displaces liquid that seems to dislodge additional solids. The tank contents rollover with a vigorous motion as seen in video cameras. When the gas and solids are transported to the surface, the reduced pressure causes the gas to expand and be released from the solids. The bulk of the gas is injected into the dome of the tank in minutes. This causes the dome to pressurize slightly. The solids, now free of the gas, can settle to the bottom of the tank and the cycle starts all over again. These cycles were occurring every 100 to 150 days.

Gas in Dome

When the gas is injected into the dome of the tank, the concentration of hydrogen at times reaches up to $5 \%$ by volume in the tank dome. This is above the lower flammable limit of hydrogen and is a safety concern. In addition, the ammonia concentration reaches up to $1.3 \%$ by volume in the tank dome. While this is well below the flammable limit for ammonia, such a concentration is a worker safety concern. The ventilation system clears the dome of flammable concentrations of hydrogen within minutes.

Temperature Observations

Tank 101-SY is instrumented with two multiple instrument trees (MITs). These MITs have ports for gas sampling in the dome, strain gauges and thermocouples. The trees extend to within four inches of the floor of the tank. The thermocouples are located approximately every 0.5 meter along the length of the tree. The temperature profiles are for only two locations in the tank but have been extremely valuable to help understand what is happening in the waste.

Figure 5 shows a typical temperature profile before and after a rollover. Notice the bulge which identifies the nonconvective layer. Above that is the flat profile of the convective layer. After the rollover, the temperatures are much more uniform, which is an indication of very thorough mixing. 


\section{Equipment for Mitigation}

Many mitigation schemes have been proposed but the one chosen for implementation was mixing the waste with a pump. This mitigation method would mimic the natural rollover by suspending gas bearing solids in a fluid, which would allow the gas to escape from the tank. The pump would be operated as necessary to mitigate the tank.

Pump

The mixer pump selected for testing in tank 241-SY-101 was a 150 horsepower submersible centrifugal pump with a design flow of $10,600 \mathrm{~L}$ (2,800 gallons) per minute and a shutoff head of $37 \mathrm{~m}(120 \mathrm{ft})$. The pump utilizes a 480-volt oil-cooled induction motor. The pump discharges the less viscous 1 iquid pumped from the upper portions of the tank through two diametrically opposed rotatable discharge nozzles, causing the nonconvective layer to thin out and release the trapped gas. The pump is instrumented with several different types of flow, temperature, strain, and pressure measuring devices to obtain optimal pump operating parameters. All electrical systems associated with the test are specifically designed for operation in a flammable gas environment (Lentsch et a1. 1994).

The pump was a spare pump originally purchased for the Hanford Grout Program. Extensive modifications were needed for mitigation purposes. The most notabie modification was to move the pump suction up so that liquid from the convective layer would be used for mixing.

The mixer pump was installed in the tank on July 3, 1993, seven days after a large gas release event, when the gas inventory remaining in the tank was at a minimum. Before installing the pump in the tank, the waste was purged with water from a special water lance to release flammable gases from the area of the pump. This reduced the release of gases while the pump was being installed into the open tank riser, and also prevented the "rollover" of the waste during pump insertion that could have damaged the pump. Figures 1 and 2 show the plan and profile views of the pump installation. The plan view shows that the pump is positioned slightly off center of the tank. The locations of the two velocity-density-temperature trees (VDTTs) and the MITs are shown. The VDTT instruments, except for the strain gauges, failed before the test but the strain gauges were useful for showing when the jet from the pump reached out to them. The temperature profiles from the MIT were very. useful in observing and understanding what is happening with the waste.

The pump nozzles were initially inserted under a deep layer of sludge so that liquid injected near the bottom would $1 \mathrm{ift}$, fracture, and undermine 1 arge sections. Once freed, these sections could rise to the base of the crust without immediately releasing their accumulated gas. The accompanying decrease in pressure expanded the gas to cause the characteristic surface leve 7 rise and drop typical of most pump-induced gas releases.

\section{Instrumentations}

Tank 101-SY has been instrumented with high sensitivity gas monitoring systems at three locations in the tank dome and in the ventilation exhaust. These systems consist of electrochemical analyzers, gas chromatographs, a mass 
spectrometer, and a Fourier transform infrared spectrometer to measure hydrogen, nitrous oxide, ammonia, and other gases in the range of approximately .0001 to 10 percent.

The tank is also instrumented with a dome space video camera, three types of level measuring instruments, and instruments that measure ventilation pressure, temperature, and relative humidity. A state-of-the-art data acquisition system has been adopted from nuclear weapons testing programs to facilitate test control and tank monitoring.

\section{Testing}

Once the mixer pump was in place and working, the testing phase began. Even though the pump was put into service after a major gas release event, there was still trapped gas in the waste. Computer modeling indicated that a large gas release event could be triggered at the start of pump testing. Therefore, the testing program was designed to start slowly and increase in vigor at a steady pace so as to remain in a safe condition while operating the pump.

\section{Pump Bump}

The nozzles of the pump were buried in the solid layer near the bottom of the tank. There was concern that the solids would enter the nozzles and plug them. To keep the nozzles clear of solids, the pump was bumped for a short period of time. Initially, the pump speed and duration of the bump was not long enough to keep the nozzles clear. A water flush had to be used at one point to clear the nozzles. Eventually, the pump bump became a 5 minute run at 1,000 rpm several times each week. This was adequate to keep the nozzles clear of solids.

\section{Phase A}

Phase A testing was carried out from July 14 to July 25, 1993 (A17emann et a]. 1994). The test consisted of short-term/low-speed pump operations intended to minimize the risk associated with the potential release of gas remaining after a rollover event. The nozzles were oriented in one direction ( 0 degrees) for the entire test. The tests started by ramping to $340 \mathrm{rpm}$ (15 ft/sec) and then running for $0,2,5$, or 10 minutes. The pump bumping during this time period was more aggressive than the testing to keep the nozzles clear.

\section{Phase B}

On completion of Phase A testing, a daily pump bump routine was initiated on July 26th. This activity continued until the start of Phase B test on October 12, 1993.

Phase B testing consisted of 24 runs. The test consisted of a series of extended-duration, phased-velocity, and tank-sweep tests. Twenty-four test runs were performed in two months. The pump flow rate was increased to $60 \mathrm{ft} / \mathrm{sec}$, and operating times were extended to 3 hours. The pump nozzles were rotated in 30 degree increments to cover the entire tank. During the initial higher speed pump runs, several large (up to 2,000 ft) gas releases 
occurred within approximately $1 \mathrm{hr}$ of pumping. These gas releases were mostly a result of gas pockets that were present in the tank before the pump was installed.

Phase B testing was completed by December 17, 1993.

\section{Ful1-Scale Testing}

After successfully completing the Phase B tests, the following operations were carried out to test the ability to fully control the tank

(Stewart et a1. 1994).

- Directional bumping. December 18, 1993 - February 2, 1994, This period was intended to allow the waste level to rise enough to give a useful surface level margin above the lower surface level. During this period, the pump was rotated 30 degrees each run and run for 5 minutes at 1,000 rpm. The bumping occurred three times a week.

- Sequence 1. February $4-25,1994$, This sequence was the most likely strategy for maintaining a constant waste level during long-term operation. The sequence was one hour runs at $750 \mathrm{rpm}$ three times a week, and rotating the nozzle 30 degree each run.

- Regrowth Test. February 28 - March 25, 1994, This test was to see how rapidly the waste level could grow after the waste was disturbed. The pump was positioned at 35 degrees and run 5 minutes at $1000 \mathrm{rpm}$ three times a week. This is thought to be the minimum pump operation that would keep the nozzles unplugged.

- Knockdown Test. March 28 - 30, 1994, This test ran 30 minutes at $750 \mathrm{rpm}$ in six directions 30 degrees apart in one day. This gave three hour run times in one day. The goat of this test was to show the tanks ability to release gas and quickly reduce the waste level.

- Jet Penetration Test. The dates for this test were Apri1 6, 8, 12, and 13, 1994. The purpose of this test was to see if the jet could penetrate into the waste. The pump was oriented at 97 degrees that pointed at a MIT, which was about 20 feet away from the pump.

\section{OBSERVATIONS SINCE TESTING}

Observations made about the behavior of the tank since testing began are discussed below. The testing has shown that the mitigation effort has had a profound effect on the gas retention in the tank.

\section{Surface Level}

One of the most important tank measurements is surface level. The surface level has responded to the storage and release of gas for many years. Figure 3 shows the surface level in the tank for about 3 years. The increase in surface level is indicative of gas being retained. The periodic drops in surface level have been times that the gas has been released in a waste rollover. Figure 3 clearly shows that the mixer pump has controlled the episodic drops. Since the mixer pump has been testing, the surface level has 
been relatively steady. The level of the tank is currently at an level not seen since the tank was originally filled. This is an indication that residual gas has been released so the gas inventory in the tank is at a lower Tevel.

Figure 4 shows some of the details of the surface level since the testing began. Notice that the surface level did rise when the tank was not being mixed. This shows that the gas generation and retention has not been solved. However, operating the pump quickly moves the waste and allows the gas to escape.

\section{Temperature}

Figure 5 shows a typical temperature profile of the tank before and after a natural gas release event. Before the event, the nonconvective layer and the convective layer are clearly evident. After the gas release event the temperature profile becomes more uniform because of the mixing of the waste during the rollover.

Figure 6 is a temperature profile in the tank after the testing phases. Both MITs are shown in this figure. Notice that the temperature profile is very uniform from top to bottom in the tank. The uniform temperature is a clear indication that the entire tank contents is well mixed by the mixer pump.

Figure 7 is a plot of temperature at various levels in the tank versus time. When the pump is turned on, the temperatures show a change almost immediateiy, even though the MITs are at least 20 feet from the pump. The change in temperature at the lower thermocouples was an indication that the pump jet was indeed excavating down through the waste. The thermocouple data shows that no more than 16 inches of waste have been left undisturbed at the bottom of the tank at the MIT.

\section{Hydrogen}

The key indicator of successful mitigation is evident in the amounts of hydrogen gas concentrations. The hydrogen gas is shown on Figure 8 . Before the mixer pump was installed and run, the hydrogen gas would exceed the lower flammable limit (LFL) frequently during the natural rollovers. This was clearly unacceptable. Since the pump has been operated, the hydrogen gas has not reached $25 \%$ of the LFL. This meets the definition of a successful mitigation of a flammable Watch List tank. The lower flammable 1 imit is $4 \% \mathrm{H}_{2}$ in air and $3 \% \mathrm{H}_{2}$ in nitrous oxide. Because nitrous oxide is a component of the gas generated within the waste, its lower flammable limit that has been used as a limit at the Hanford Site.

Figure 9 shows in greater detail the hydrogen concentration during the testing period. The hydrogen increases whenever the pump is operated. Commonly, the hydrogen concentration would decrease for a few hours and then increase above the base line. At times during the phase B testing, the pump has stimulated a rather substantial release of hydrogen. As the waste became depleted in residual gas, the amount of hydrogen released by the pump decreases. The recent pump runs have caused the release of only a minimal amount of hydrogen. 
HHC-SA-2305-FP

\section{Other Gases}

Other gases besides hydrogen are released from the waste. Nitrous oxide and ammonia are two of the major gases that are released. Nitrous oxide is released at about the same concentration as the hydrogen, while the release of ammonia is a lesser amount. Ammonia is soluble in aqueous solutions and appears to be released differently than the insoluble gases.

The concentrations of released nitrous oxide resemble the concentrations of released hydrogen. Since testing the ammonia gas has shown a marked decrease in the baseline concentration. This could be for two reasons. The first reason is that the ammonia is the product of a hydrogen. and nitrous oxide reaction caused by the radiation. Because of the lower hydrogen and oxide concentrations in the waste, the rate of ammonia release may be less. The second reason is that the ammonia is defusing through a crust at the surface. The suspension of solids in the solution suppresses the diffusion rate. The rate of ammonia release has definitely been lowered by pump testing.

\section{CONCLUSIONS}

Jet pumping can successfully mitigate a flammable gas Watch List tank such as 101-SY. Jet pumping allows gas to be carefulty released when desired. Over time, the residual gas in the waste can be released. The jet pump can then be operated to release the gas which is formed before enough is trapped to cause a natural rollover. The mixer pump has been successful in suspending essentially all of the settled solids and keeping the solids in suspension.

Using the jet pump technique, the hydrogen concentrations can be kept at a safe limit, which is below $25 \%$ of the LFL. The hydrogen generated can be released as desired in a safe and cautious manner.

Future plans are to move from a testing mode to an operation mode. The operation mode will operate the pump periodically, several times a week. The duration of the run and the direction of the jet will be adjusted to keep the solids in suspension and provide a mechanism for release of gases.

\section{References:}

Allemann, R. T., Z. I. Antoniak, H. D. Chvala, L. E. Efferding, J. G. Fadeff, J. R. Friley, W. B. Gregory, J. D. Hudson, J. J. Irwin, N. W. Kirch, T. E. Michener, F. E. Panisko, C. W. Stewart, B. M. Wise, 1994, Mitigation of Tank 241-SY-101 by Pump Mixing: Results of Testing Phases $A$ and $B$, PNL-9423, Pacific Northwest Laboratory, Richland, Washington.

Lentsch, J. W., H. Babad, C. E. Hanson, N. W. Kirch, 1994, Progress Toward Mitigation of Flammable Gas Tank 241-SY-101, Westinghouse Hanford Company, Richland, Washington.

Stewart, C. H., J. D. Hudson, J. R. Friley, F. E. Panisko, Z. I. Antoniak, J. J. Irwin, J. G. Fadeff, L. F. Efferding, T. E. Michener, N. W. Kirch, D. A. Reynolds, 1994, Mitigation of Tank 241-SY-101 by Pump Mixing: Results of Ful7-Scale Testing, PNL-9959, Pacific Northwest Laboratory, Richland, Washington. 
Reynolds, D. A., H. Babad, 1994 "Cyclic Gas Releases in Hanford Site Nuclear Waste Tanks," Chapter 13, Emerging Technologies in Hazardous Waste Management IV, ACS Symposium Series 554, American Chemical Society. 
WHC-SA-2305-FP

Figure 1. Plan View of Tank 241-SY-101

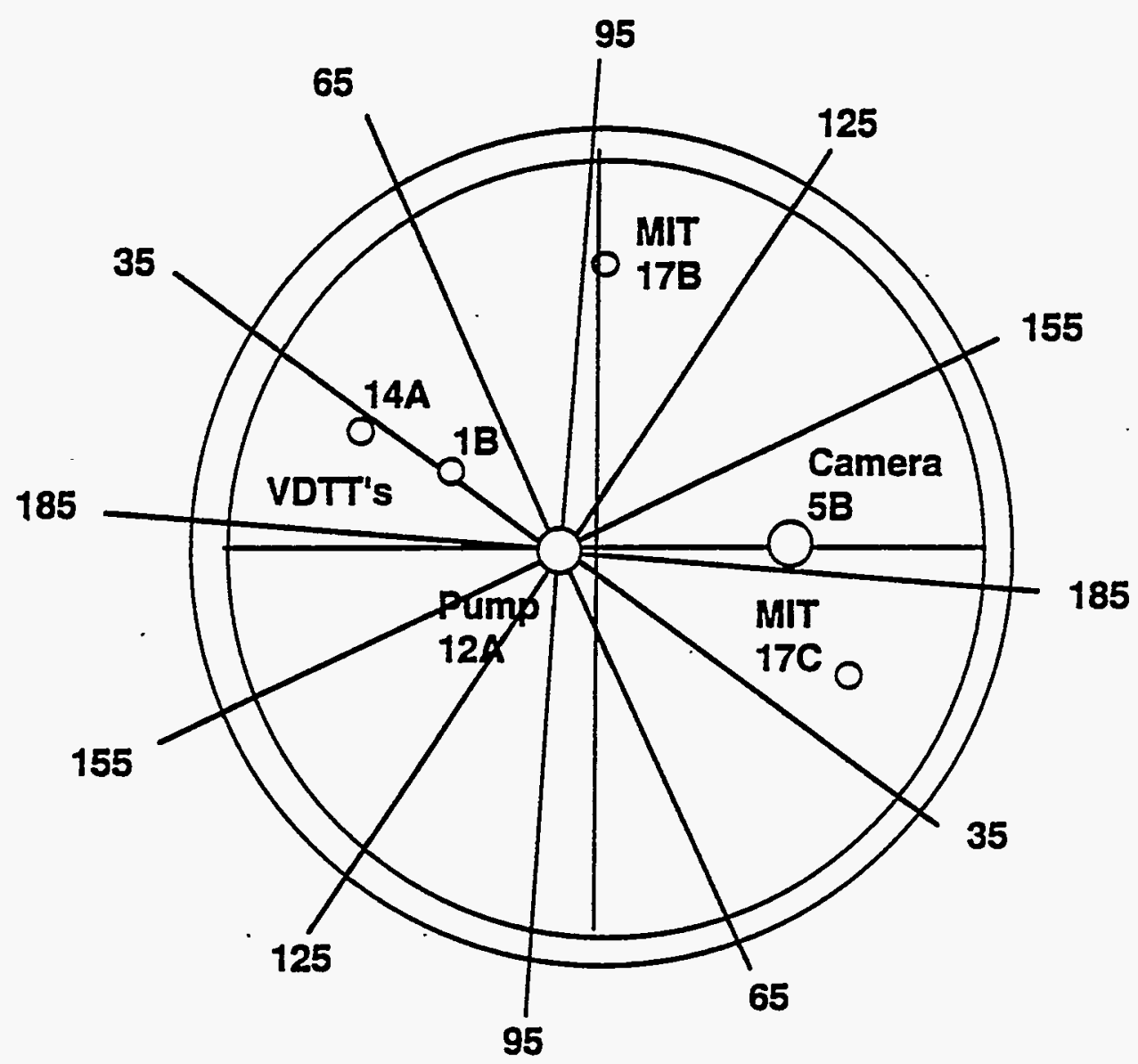


Figure 2. Tank 241-SY-101 Hydrogen Mitigation Test Pump

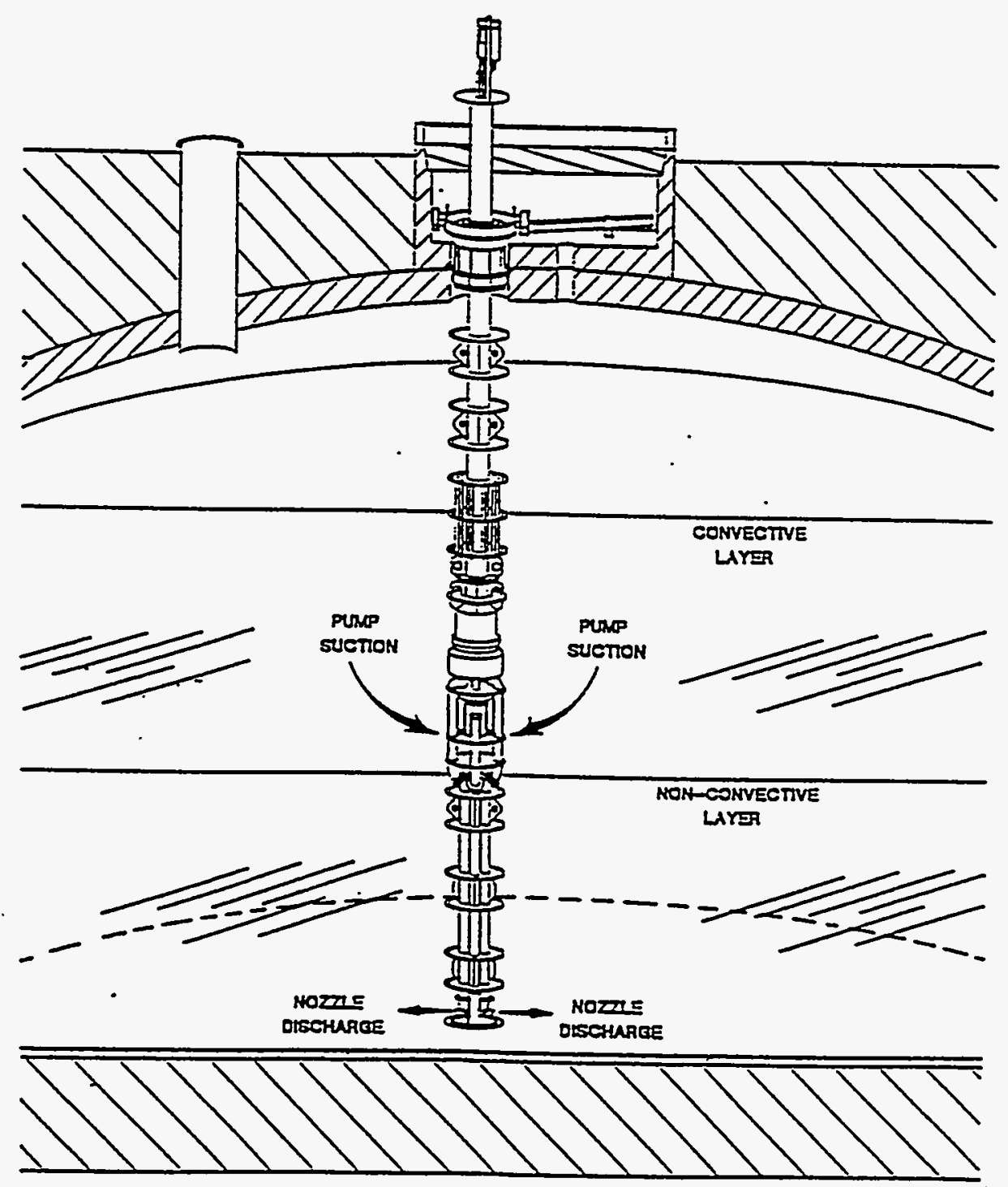


WHC-SA-2305-FP

Figure 3. Surface Leve1 from August 1, 1991 to August 1, 1994

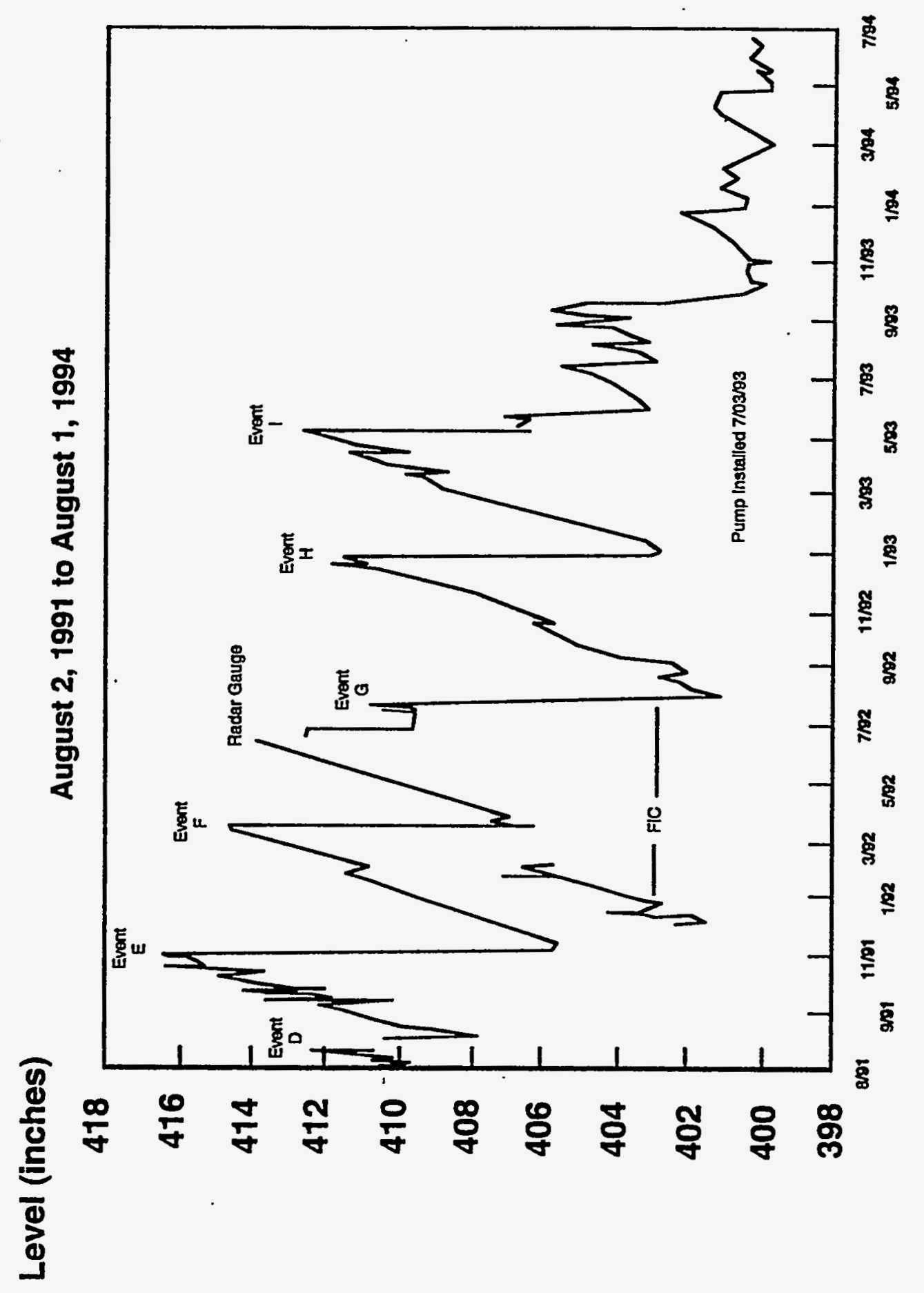


WHC-SA-2305-FP

Figure 4. Surface Leve1 During Mixer Pump Testing

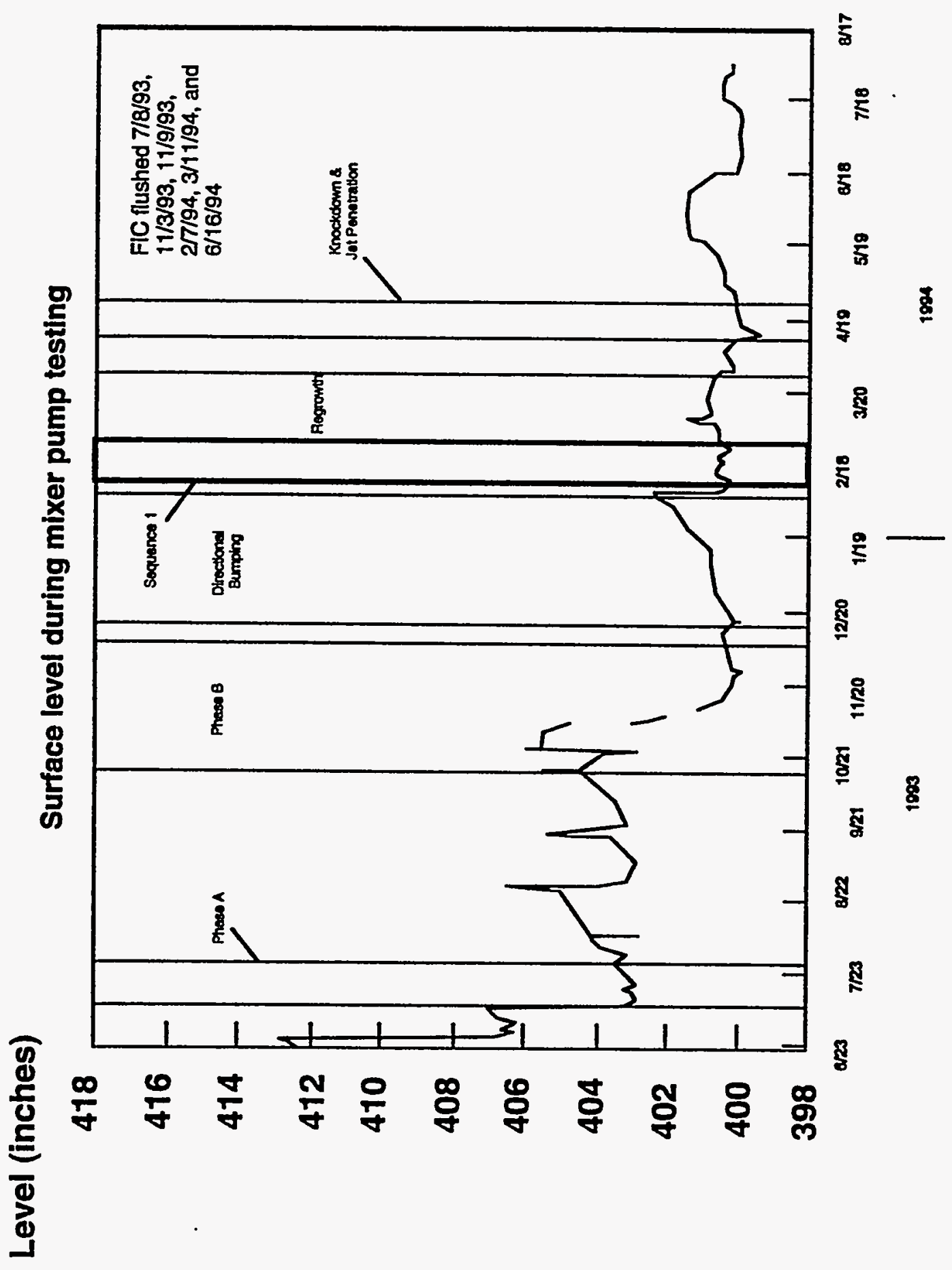


Level (inches)

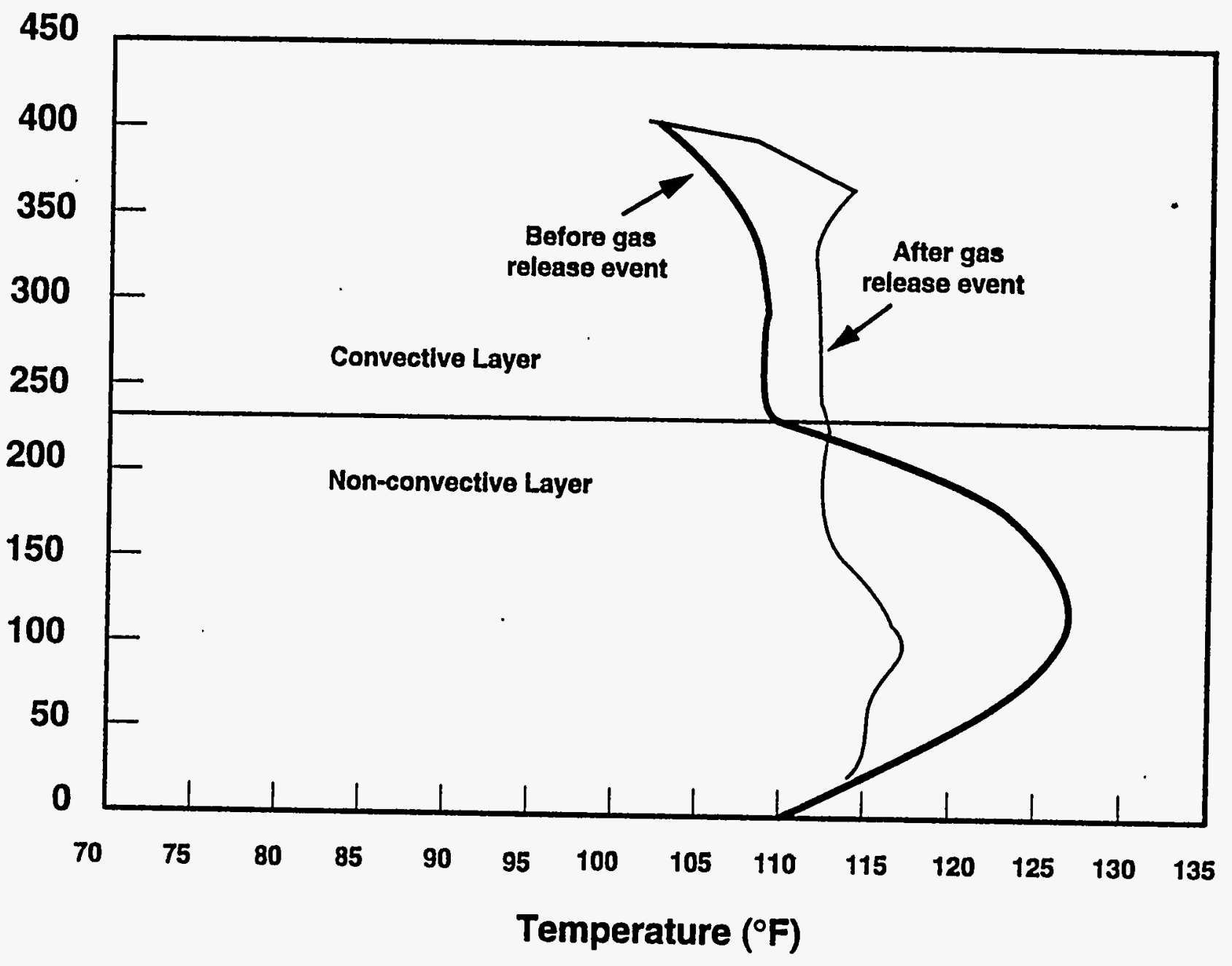


HHC-SA-2305-FP

Figure 6. Temperature Profile Currently in Tank

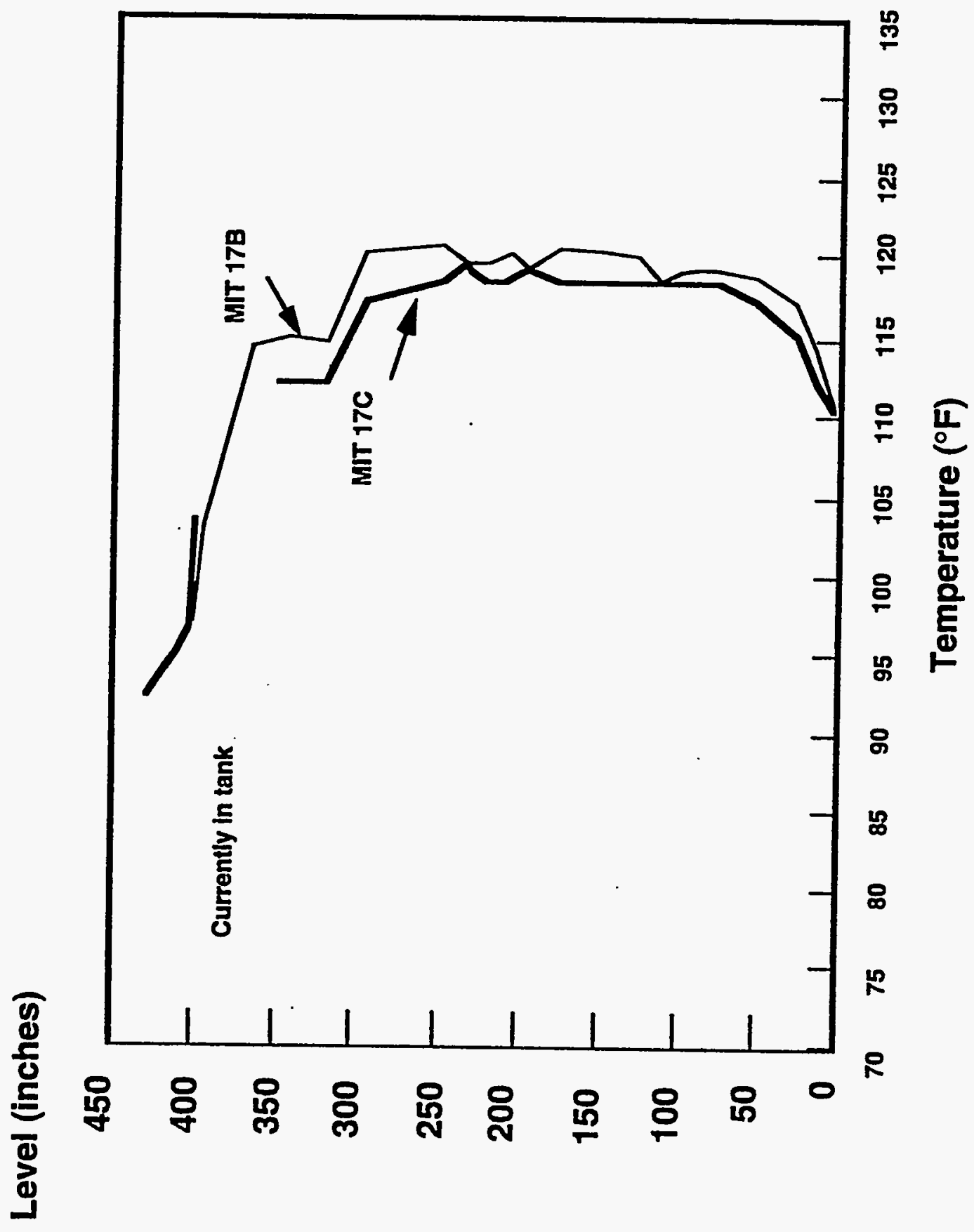




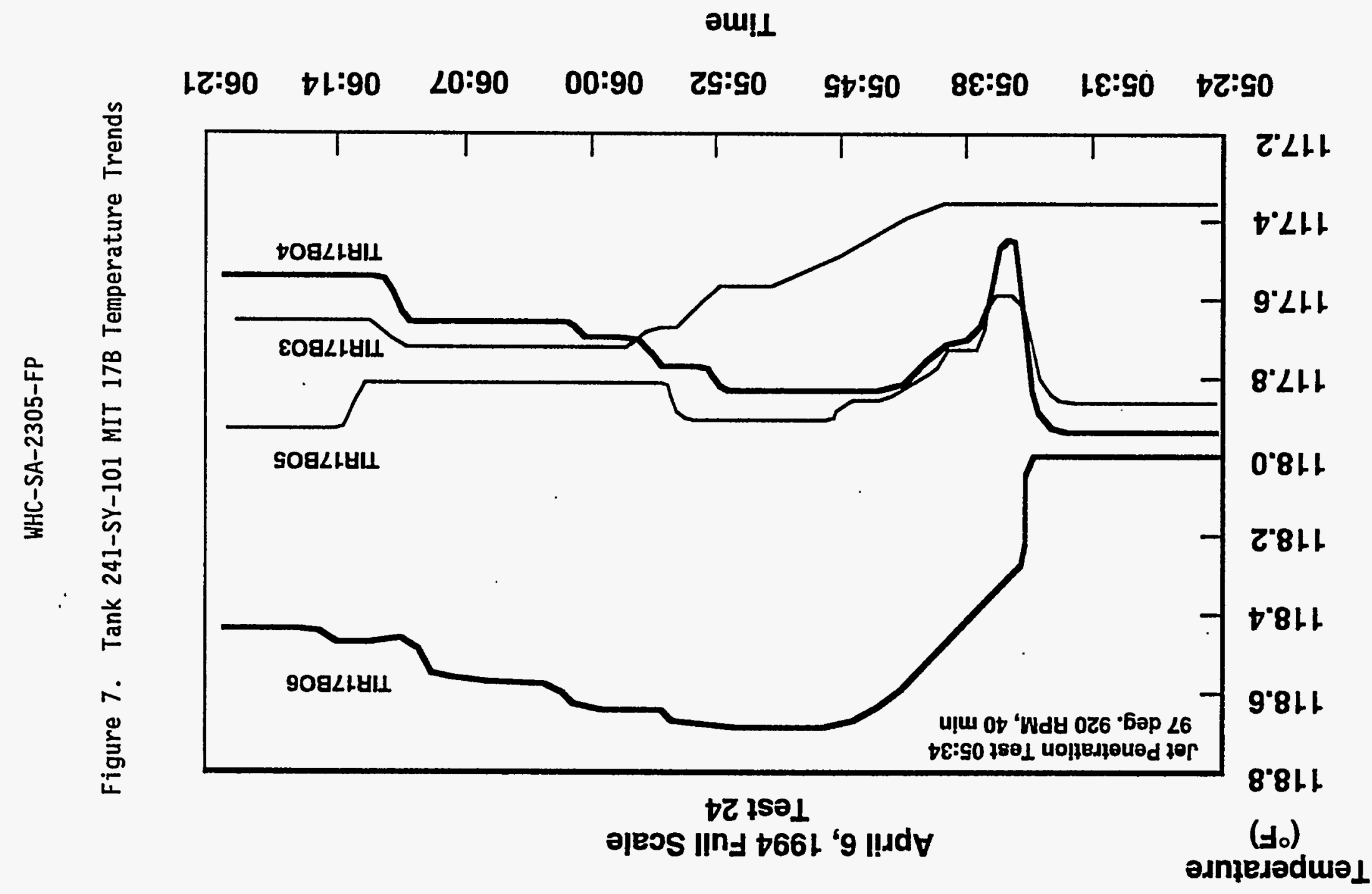


WHC-SA-2305-FP

Figure 8. Hydrogen Concentration in the Dome Space

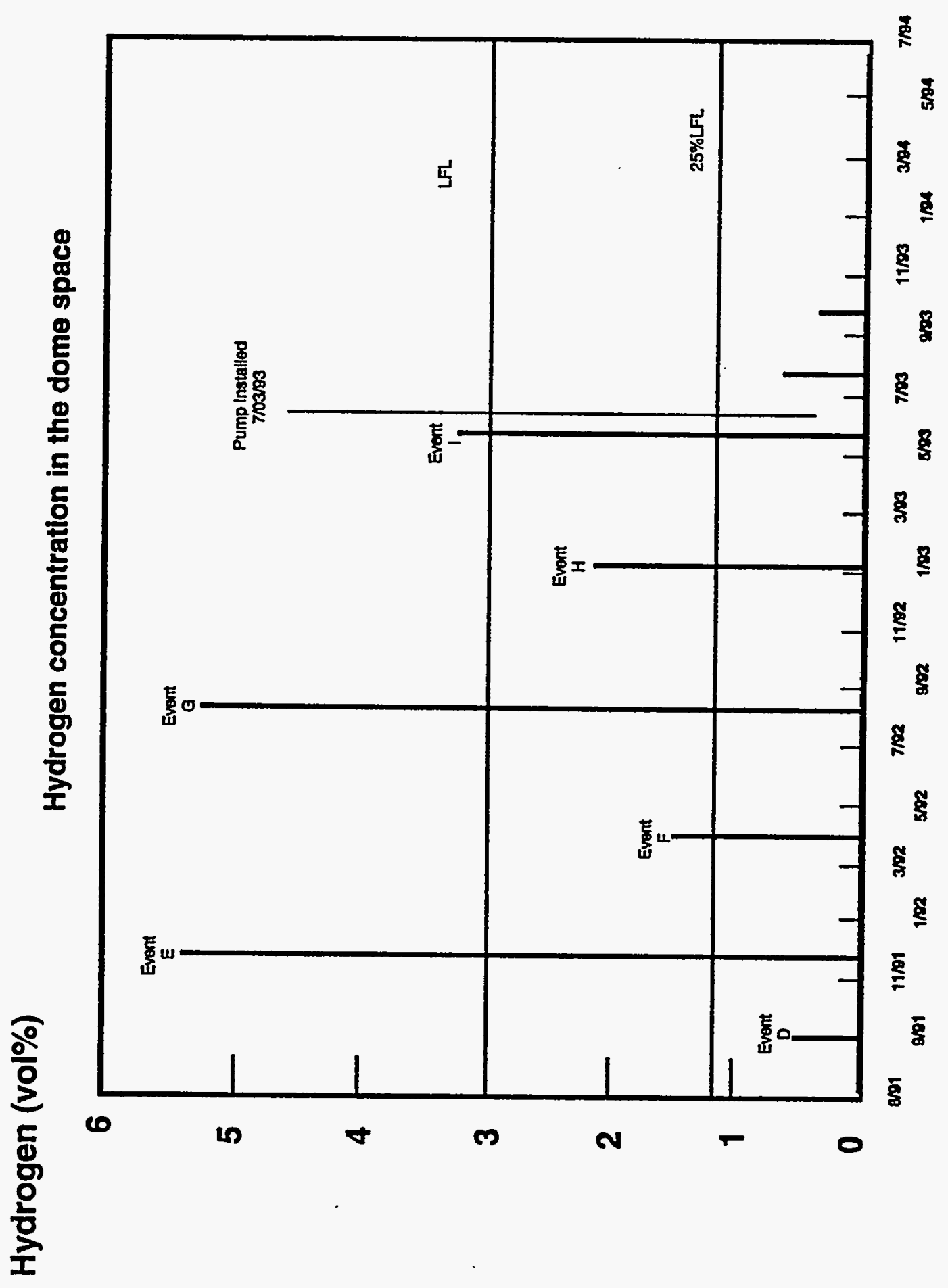



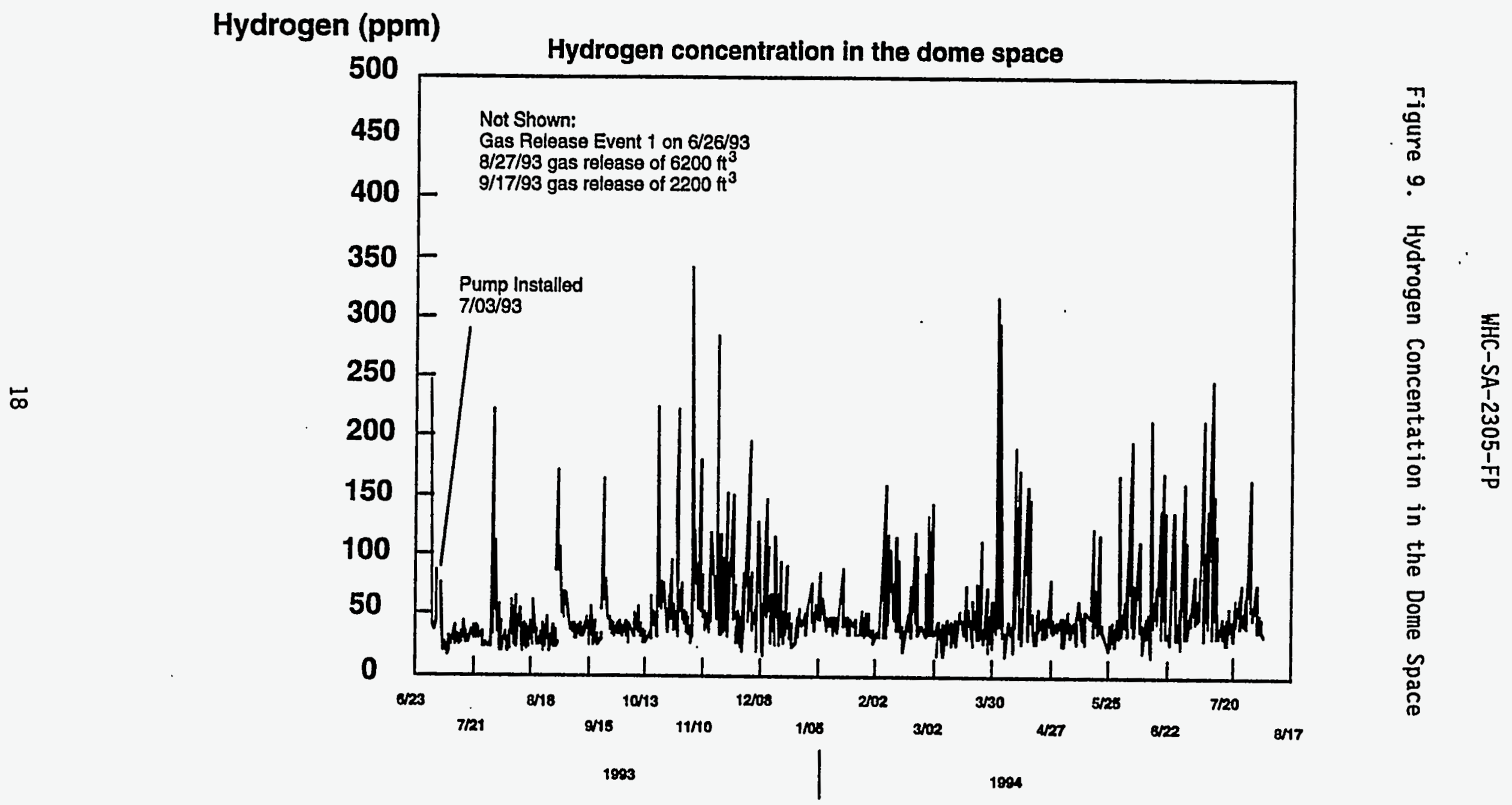